\title{
A QUALIDADE DA LUZ AFETA O AFILHAMENTO EM PLANTAS DE TRIGO, QUANDO CULTIVADAS SOB COMPETIÇÃO ${ }^{1}$
}

\author{
LIGHT QUALITY AFFECTS TILLERING ON WHEAT WHEN GROWN UNDER COMPETITION
}

\author{
Milton Luiz de Almeida ${ }^{2}$ Claudio Mario Mundstock ${ }^{3}$
}

\section{RESUMO}

O presente trabalho foi conduzido com o objetivo de verificar os efeitos da mudança na qualidade da luz sobre a emissão de afilhos e na sua acumulação de massa seca. A cultivar de trigo EMBRAPA 16 foi cultivada em comunidades de aproximadamente $400 \mathrm{p} / \mathrm{m}^{2}$, em condições naturais de radiação durante o inverno, no Sul do Brasil. No primeiro experimento (baixa qualidade de luz), utilizaram-se filtros verde e vermelho entre as linhas, entre os estádios Haun de 1.0 a 3.1. No segundo experimento (melhor qualidade de luz), as plantas foram suplementadas durante o dia com luz vermelha (V) (660nm), entre os estádios Haun 1.0 e 3.1. Já no terceiro experimento (baixa qualidade de luz), as plantas foram suplementadas durante o dia com luz vermelha extrema (Ve) (730nm), entre os estádios Haun 1.0 e 3.1. A qualidade da luz afetou a emissão de afilhos, sua massa seca e sua distribuição entre o colmo principal e os afilhos. A baixa qualidade da luz (filtros verde e vermelho e luz Ve) induziu as plantas a emitir menos afilhos com menos massa seca/afilho. A baixa qualidade da luz priorizou o colmo principal sob condições de comunidades, antes que tivesse sido estabelecida a competição pela quantidade total de luz recebida pelas plantas. A melhor qualidade de luz (luz V) teve efeito oposto. Os afilhos foram emitidos em maior número e a alocação de massa seca foi menos priorizada para o colmo principal do que nos tratamentos com baixa qualidade.

Palavras-chave: emissão de afilhos, luz vermelha e vermelha extrema, acúmulo de massa seca, trigo.

\section{SUMMARY}

The selective absortion of red light by foliage changes the light quality in plant communities. This work was conducted to determinate if plants can detect those early modifications by changing tiller emission and dry mass accumulation. Embrapa 16 wheat cultivar was grown at approximatelly $400 \mathrm{p} / \mathrm{m}^{2}$ under natural radiation conditions during wintertime, in Southern Brazil. On the first experiment (poor light quality), green and red filters were placed between rows, from Haun stages 1.0 to 3.1. For the second experiment (good light quality), low fluence red light (660nm) was supplemented during the day from Haun stage 1.0 to 3.1. In the third experiment (poor light quality) low fluence far-red light (730nm) was supplemented during the day from Haun stage 1.0 to 3.1. Light quality affected tiller emission, tillers dry mass and mass allocation between mainstem and tillers. Poor light quality (filters that reduced red light and light supplementation) induced plants to emit less tillers with less dry mass per tiller. Poor light quality priorized mainstem against dry mass under community conditions, even if there was not a real competition for the total amount of light received by plants. Good light quality (red light supplementation) had the opposite effect. Tillers were emitted in higher amounts and mass allocation for mainstem was less than for low light quality treatments.

Key words: tiller emission, red and far-red light, dry mass allocation, wheat.

\section{INTRODUÇÃO}

A competição entre plantas em comunidades se inicia muito cedo afetando, precocemente, a dominância apical. Esta inibe o crescimento de órgãos laterais, e o grau de inibição depende do genótipo, do ambiente e da idade da planta. A dominância apical é influenciada pela qualidade da luz, ou seja, pela razão entre os valores de radiação vermelha $(\mathrm{V})$ e vermelha extrema $(\mathrm{Ve})$ da radiação total incidente (BALLARÉ $\boldsymbol{e t}$ al., 1992a; SCHMITT \& WULFF, 1993). No entanto, os mecanismos pelos quais essa razão influencia a dominância apical são ainda desconhecidos (MARTIN, 1987). Os efeitos

\footnotetext{
${ }^{1}$ Extraído de parte da tese de doutorado do primeiro autor.
}

${ }^{2}$ Engenheiro Agrônomo, Doutor, Professor da Faculdade de Agronomia da Universidade do Estado de Santa Catarina, CP 281, 88520000, Lages, SC. E-mail: milton@ cav.udesc.br. Autor para correspondência. Bolsista do CNPq.

${ }^{3}$ Engenheiro Agrônomo, PhD., Professor da Faculdade de Agronomia da Universidade Federal do Rio Grande do Sul. CP 776, 91501970, Porto Alegre, RS. E-mail: cmmundst@vortex.ufrgs.br. Bolsista do CNPq. 
da qualidade da luz sobre o crescimento e desenvolvimento se manifestam precocemente sobre as plantas, antes de qualquer redução na radiação fotossinteticamente ativa (BALLARÉ et al., 1987). Isso porque os sinais de luz percebidos pelo fitocromo desempenham função na detecção do nível de competição que as plantas irão encontrar, principalmente quando a competição tende a ser intensa (SCHMITT \& WULFF, 1993).

A qualidade da luz pode ter um papel crítico na determinação da emissão, desenvolvimento e sobrevivência dos afilhos. A luz é modificada precocemente em comunidades de plantas (BALLARÉ $\boldsymbol{e} t$ $\boldsymbol{a l} .$, 1987) e, dessa forma, também podem ser modificadas, precocemente, a emissão e a sobrevivência de afilhos. MEROTTO JUNIOR (1995) mostra que esses dois processos estão relacionados, então, podem afetar a sobrevivência dos afilhos, os quais participam como parte dos componentes do rendimento das plantas e como prováveis supridores de assimilados ao colmo principal. As relações entre o colmo principal e os afilhos afetam o número de afilhos férteis em cereais e isso depende das condições ambiente presentes durante a iniciação do primórdio do afilho e em estádios de desenvolvimento subseqüentes. Segundo MASS et al. (1994), estresses do ambiente durante a emergência dos afilhos podem inibir a sua formação e, em estádios posteriores, podem causar a sua senescência precoce.

A senescência precoce de afilhos é particularmente crítica nas condições de cultivo de trigo no Sul do Brasil, onde o número de espigas produzidas por unidade de área é considerado muito baixo (GALLI, 1996) e, conforme WOBETO (1994), mesmo o número de afilhos emitidos sendo elevado, sua sobrevivência é extremamente baixa. Nesse sentido, a taxa de crescimento dos afilhos destaca-se como um dos principais aspectos que levam à sobrevivência. Para que um afilho sobreviva, a primeira condição é que a sua taxa de crescimento seja similar à do colmo principal (CP). Quanto mais as taxas dos afilhos se distanciarem das taxas do $\mathrm{CP}$, menores são as probabilidades de sobrevivência (WOBETO, 1994). As taxas de crescimento foliar do $\mathrm{CP}$ e dos afilhos são iguais em situação sem estresse (MASLE, 1985), mas WOBETO (1994) verificou que quando ocorre maior competição entre plantas por fatores do meio, o crescimento do CP é mais acelerado do que o dos afilhos. Dessa forma, a modificação precoce na qualidade da luz pode ser um destes fatores que afetam o crescimento foliar do $\mathrm{CP}$ e dos afilhos.

A modificação na qualidade da luz é devido a absorção da luz vermelha e a não absorção da luz vermelha extrema. Isso proporciona condições variáveis de disponibilidade de radiação nos diferentes extratos de uma comunidade e, dessa forma, é modificada a razão V:Ve. Essa razão, percebida pelo caule das plantas, indica a proximidade entre as plantas e induz a alterações na morfologia e na alocação de assimilados (BALLARÉ $\boldsymbol{e t} \boldsymbol{a l}$., 1992a). Isso pode ser um dos motivos da modificação de acumulação de massa seca entre os diferentes órgãos, como demonstrado por WOBETO (1994) quando comparou o sincronismo nas taxas de acumulação entre o $\mathrm{CP}$ e o primeiro (A1) e o segundo (A2) afilhos, em situação de lavoura com diferentes cultivares. A modulação fotomorfogênica pela razão V:Ve foi observada em plantas de cevada por DAVIS \& SIMMONS (1994), demonstrando que as plantas têm a capacidade de detectar e responder morfologicamente à alteração da qualidade da luz.

$\mathrm{O}$ entendimento de como as plantas detectam, respondem e se adaptam aos estímulos do ambiente é muito importante para a melhor exploração agrícola dos genótipos hoje disponíveis. No entanto, estes estudos devem ser realizados em ambientes que simulem as situações de lavoura, ou seja, em ambiente com radiação natural e plantas crescendo em densidade de cultivo. Alguns trabalhos já verificaram os efeitos da variação da qualidade da luz sobre o afilhamento, mas foram conduzidos em baixa densidade de plantas (DEREGIBUS et al., 1983; CASAL et al., 1986) ou em baixa disponibilidade de radiação (CASAL et al., 1985; BARNES \& BUGBEE, 1991). Dessa forma, através da condução de experimentos em ambiente com radiação natural e em densidade de cultivo, o presente trabalho teve como objetivo a verificação dos efeitos da modificação na qualidade da luz sobre o processo de emissão e acumulação de massa seca dos afilhos.

\section{MATERIAL E MÉTODOS}

Três experimentos foram realizados com trigo (cultivar EMBRAPA 16) para verificar os efeitos da qualidade da luz na emissão de afilhos e na sua acumulação de massa seca. Um experimento foi realizado com filtro verde, visando a diminuir a radiação na faixa do vermelho. Os outros dois experimentos foram realizados com suplementação luminosa com luz vermelha (V) e com luz vermelha extrema (Ve). A expressão "maior ou menor qualidade da luz", no texto, refere-se às modificações entre a disponibilidade de luz V e Ve. Assim, a diminuição de luz $\mathrm{V}$, ou o aumento de luz Ve foi considerada como diminuição da qualidade da luz na comunidade. Da mesma forma, o aumento 
da quantidade de luz $\mathrm{V}$ foi considerada como aumento da qualidade da luz.

Os experimentos foram conduzidos em Porto Alegre, RS, sendo as plantas cultivadas em caixas de madeira com $1,2 \mathrm{~m}$ de largura, $1,5 \mathrm{~m}$ de comprimento e $30 \mathrm{~cm}$ de altura, em telado. As linhas foram semeadas na direção norte-sul, num espaçamento entrelinhas de $17 \mathrm{~cm}$. As cinco (primeiro experimento) e quatro linhas (segundo e terceiro experimentos) centrais constituíram a área útil, sendo considerada cada uma dessas linhas como uma repetição. Cada repetição foi constituída por 20 plantas em competição, ou seja, num mesmo estádio de desenvolvimento e não isoladas. As duas linhas externas foram consideradas como bordadura. $\mathrm{O}$ delineamento experimental utilizado foi o completamente casualizado. As plantas, dos três experimentos, foram cultivadas em um substrato constituído da mistura uniforme de solo mineral e cama de aviário, com as seguintes características: $26 \%$ de argila; 5,4 de $\mathrm{pH}$ (em água); $20 \mathrm{mg} \cdot \mathrm{kg}^{-1}$ de $\mathrm{P}, 100 \mathrm{mg} \cdot \mathrm{kg}^{-1}$ de $\mathrm{K}, 25 \mathrm{mg} \cdot \mathrm{kg}^{-1}$ de matéria orgânica, $0,4 \mathrm{cmo} \ell_{\mathrm{c}} \cdot \mathrm{kg}^{-1}$ de $\mathrm{Al}$, $2,4 \mathrm{cmo} \ell_{\mathrm{c}} \cdot \mathrm{kg}^{-1}$ de Ca e; $1,1 \mathrm{cmo} \ell_{\mathrm{c}} \cdot \mathrm{kg}^{-1} \mathrm{de} \mathrm{Mg}$.

O primeiro experimento foi realizado com filtros de papel celofane colocados entre as linhas de plantas. Ele foi implantado em 02 de maio de 1996, com sementes com diâmetro transversal superior a $2,0 \mathrm{~mm}$, tendo a emergência ocorrida oito dias após. Três dias após a emergência, foi realizado o desbaste para a obtenção da densidade de 400 plantas por $\mathrm{m}^{-2}$.

Os tratamentos consistiram de tiras de filtros de papel celofane vermelho, verde e transparente, com $5,0 \mathrm{~cm}$ de altura e $1,5 \mathrm{~m}$ de comprimento, colocadas exatamente a $8,5 \mathrm{~cm}$ das linhas de semeadura, na direção vertical. As tiras foram fixadas na direção vertical através de palitos. Em cada tratamento, foi colocado um tipo de filtro.

A transmitância dos filtros foi determinada em espectrofotômetro marca Beckman, modelo DU65, entre os comprimentos de onda de 400 a $800 \mathrm{~nm}$, a intervalos de 40nm (Figura 1). Os tratamentos foram aplicados quando as plântulas estavam com a primeira folha totalmente expandida (15/05/96) e foram retirados 14 dias após a aplicação (29/05/96), no estádio 3.1 da escala proposta por Haun (1973). Os filtros foram substituídos sempre que apresentassem diminuição de sua coloração, em média a cada 5 dias.

Os tratos culturais foram realizados de forma que não houvesse qualquer interferência sobre as plantas. Dessa forma, plantas daninhas e pragas foram controladas imediatamente após o seu aparecimento. A adubação nitrogenada foi realizada no estádio 3.1 da escala Haun com uréia, numa dose de $60 \mathrm{~kg} \cdot \mathrm{ha}^{-1}$ de nitrogênio. A coleta das plantas foi

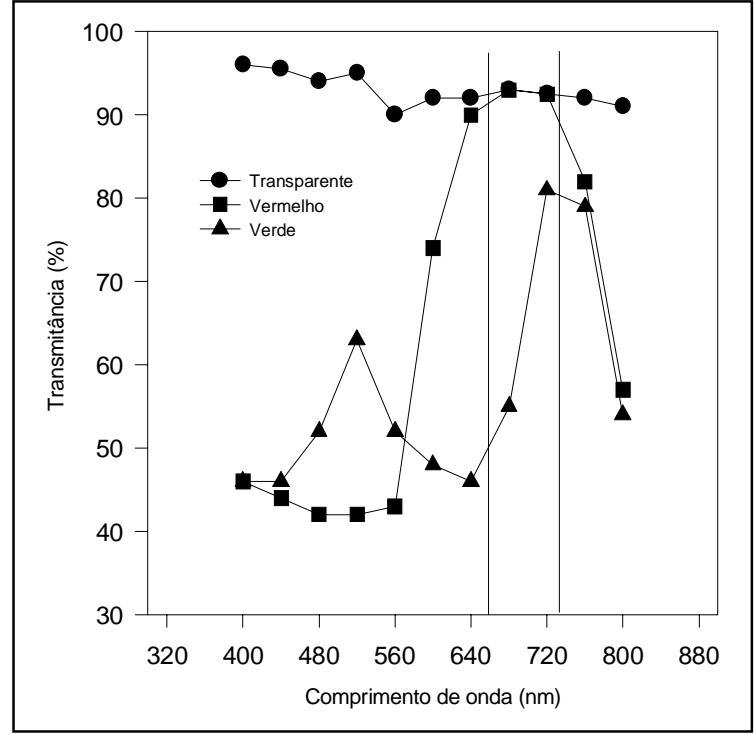

Figura 1 - Transmitância dos filtros de celofane transparente, verde e vermelho determinada em espectrofotômetro marca Beckman, modelo DU65. Barras verticais indicam os comprimentos de onda da luz vermelha (660nm) e luz vermelha extrema (730nm). FA/UFRGS, Porto Alegre, RS, 1996.

realizada 32 dias após a emergência, no estádio 4.6 da escala Haun. No período de realização do primeiro experimento, a temperatura média máxima, média mínima e média foram $21,5{ }^{\circ} \mathrm{C}, 13,1{ }^{\circ} \mathrm{C}$ e $17,2{ }^{\circ} \mathrm{C}$, respectivamente.

O segundo experimento foi realizado com suplementação de luz, durante o dia (das 7 às 18), na faixa do vermelho e o terceiro experimento, com suplementação de luz, durante o dia (das 7 às 18h) na faixa do vermelho extremo. Esses experimentos foram realizados de forma semelhante ao primeiro experimento, utilizando o mesmo substrato, mas na semeadura foram utilizadas sementes prégerminadas. A utilização de sementes prégerminadas e o plantio com pinças e réguas foram realizados objetivando maior uniformidade entre plantas da comunidade. A pré-germinação foi realizada a uma temperatura aproximada de $25^{\circ} \mathrm{C}$ e $100 \%$ de umidade relativa do ar. As plântulas, apresentando a protusão da radícula e do coleoptile foram colocadas na linha à distância de $1,5 \mathrm{~cm}$ entre si, o que determinou uma densidade de 392 plantas por $\mathrm{m}^{-2}$.

O segundo experimento foi transplantado em 28 de julho de 1996 e a emergência da primeira folha ocorreu três dias após a semeadura. Os tratamentos que fizeram parte desse experimento foram: a) suplementação com luz vermelha direta (plantas que estavam embaixo da fonte de luz); b) suplementação com luz vermelha a $60 \mathrm{~cm}$ (plantas que estavam a $60 \mathrm{~cm}$ da fonte de luz) e; c) suplementação 
com luz vermelha a $180 \mathrm{~cm}$ (plantas que estavam a $180 \mathrm{~cm}$ da fonte de luz). Os tratamentos B e C foram obtidos através da coleta de plantas a 60 e $180 \mathrm{~cm}$ da fonte de luz aplicada no tratamento A. A adição de luz foi iniciada quando as plântulas apresentavam uma folha totalmente expandida, aos sete dias após a emergência e foi encerrada no estádio 3.1 da escala Haun, aos 21 dias após a emergência.

A luz vermelha foi adicionada através da conjugação de quatro lâmpadas fluorescentes de 20w, acopladas em uma calha de 1,0m de comprimento e duas folhas de papel celofane vermelho, colocadas imediatamente abaixo das lâmpadas. Esse conjunto proporciona uma densidade de fluxo aproximado de $0,012 \mathrm{w} \cdot \mathrm{m}^{-2} \cdot \mathrm{nm}^{-1}$ (CARDOSO, 1995) o que eqüivale a $0,055 \mu \mathrm{mo} \ell \cdot \mathrm{m}^{-2} \cdot \mathrm{s}^{-1}$ conforme transformação proposta por THIMIJAN \& HEINS (1983). Essa quantidade de luz é considerada baixa, ou seja, praticamente sem efeito sobre a taxa fotossintética (TAIZ \& ZEIGER, 1991). Essa calha foi colocada transversalmente à direção das linhas das plantas, $40 \mathrm{~cm}$ acima das plantas que formavam o tratamento A. O papel celofane foi substituído à medida que havia diminuição de sua coloração, em média a cada quatro dias.

O terceiro experimento foi transplantado em $1^{\circ}$ de agosto de 1996 e a emergência ocorreu em três dias. A metodologia de condução desse experimento foi semelhante ao segundo experimento, diferindo apenas nos tratamentos, que foram os seguintes: a) suplementação com luz vermelha extrema (Ve) direta (plantas que estavam embaixo da fonte de luz); b) suplementação com luz vermelha extrema a $60 \mathrm{~cm}$ (plantas que estavam a $60 \mathrm{~cm}$ da fonte de luz) e; c) suplementação com luz vermelha extrema a $180 \mathrm{~cm}$ (plantas que estavam a $180 \mathrm{~cm}$ da fonte de luz). Os tratamentos B e C foram obtidos através da coleta de plantas a 60 e $180 \mathrm{~cm}$ da fonte de luz aplicada no tratamento A. A adição de luz foi iniciada, quando as plântulas apresentavam uma folha totalmente expandida, aos sete dias após a emergência e foi encerrada no estádio 3.1 da escala Haun, aos 21 dias após a emergência.

A luz Ve foi obtida através de dois conjuntos, cada qual com uma lâmpada incandescente de 40w, acoplada em holofotes, com duas folhas de papel celofane azul e duas folhas de papel celofane vermelho, colocadas imediatamente abaixo da lâmpada. Cada conjunto proporciona uma densidade de fluxo aproximado de $0,012 \mathrm{w} \cdot \mathrm{m}^{-2} \cdot \mathrm{nm}^{-1}$ (CARDOSO, 1995), o que eqüivale a $0,060 \mu m o \ell . \mathrm{m}^{-2} . \mathrm{s}^{-1}$ conforme transformação proposta por THIMIJAN \& HEINS (1983). Essa quantidade de luz também é considera- da baixa (TAIZ \& ZEIGER, 1991). Os dois conjuntos foram colocados a $40 \mathrm{~cm}$ acima das linhas de cultivo do tratamento A e distribuídos de forma eqüidistante na largura das caixas. O papel celofane foi substituído à medida que havia diminuição de sua coloração, em média a cada quatro dias.

Os tratos culturais foram realizados de forma que não houvesse qualquer interferência sobre as plântulas no segundo e terceiro experimento. A adubação nitrogenada foi realizada no estádio 3.1 da escala Haun, numa dose de $60 \mathrm{~kg} \cdot \mathrm{ha}^{-1}$ de nitrogênio. A coleta das plantas foi realizada 33 dias após a emergência em ambos os experimentos, sendo no estádio 5.1 da escala Haun para o segundo experimento e, no estádio 4.8 da escala Haun, para o terceiro experimento. No período de realização do segundo e do terceiro experimentos, a temperatura média máxima, média mínima e média foram de $20,1^{\circ} \mathrm{C}, 12,4^{\circ} \mathrm{C}$ e $16,5^{\circ} \mathrm{C}$, respectivamente.

Os métodos de coleta e determinação das variáveis foram similares em todos os experimentos. As 20 plantas coletadas de cada repetição foram separadas em colmo principal (CP) e afilhos, sendo os afilhos de ordem mais elevada agrupados com os afilhos primários das mesmas folhas (ex.: A1.1 junto com o A1). A denominação de folhas e afilhos foi adaptada do padrão utilizado por MASLE (1985). O afilhos foram denominados pela letra A, seguido do número da folha de cujo nó são originados. Dessa forma: CP - colmo principal; A0 - afilho originado do nó do coleoptile; A1 - afilho originado do nó da primeira folha do CP; A1.1 - afilho originado do nó da primeira folha do A1; An - afilho originado do nó da enésima folha do CP. Após a separação, o CP e os afilhos foram colocados separadamente em sacos de papel para secagem em estufa de fluxo de ar contínuo, a aproximadamente $60^{\circ} \mathrm{C}$, até massa constante. Foram realizadas as seguintes determinações: massa seca (MS) do CP; MS total obtida pelo somatório de MS do CP e dos afilhos; razão de massa entre CP e afilhos; somatório de MS dos afilhos de 20 plantas (MS dos afilhos presentes nas 20 plantas amostradas); MS por afilho (obtido pela divisão entre a MS dos afilhos presentes em 20 plantas e o número de afilhos); \% de afilhos emitidos (percentual de plantas com a presença de cada um dos afilhos primários analisados).

Os dados de todos os experimentos foram analisados estatisticamente através da técnica da análise da variância. Quando alcançada significância estatística, as médias foram comparadas pelo teste de Duncan em nível de 5\% de probabilidade de erro. 


\section{RESULTADOS E DISCUSSÃO}

A detecção da alteração da qualidade da luz e a conseqüente interação entre plantas, em comunidade, foi observada antes mesmo das plantas começarem a competir efetivamente por quantidade de luz (Tabela 1). Isso foi verificado nos experimentos em que a qualidade da luz foi modificada através do uso de filtros e iluminação artificial, em condições naturais de cultivo, através do padrão de alocação de massa seca (MS) entre órgãos. Para tanto, foi analisada a MS acumulada no colmo principal (CP), em toda a planta e a razão de massa entre o CP e os afilhos.

A menor qualidade da luz, obtida através do uso do filtro verde nas entrelinhas de cultivo, resultou em menor acúmulo de MS nos afilhos $\mathrm{A} 1 \mathrm{e}$ A2, menor MS por afilho A2, menor emissão do A2, menor acúmulo MS no $\mathrm{CP}$ e em toda a planta e maior razão de MS entre o $\mathrm{CP}$ e os afilhos (Tabela 1). Nesse experimento, também, utilizaram-se um tratamento com filtro transparente e outro com filtro vermelho. O filtro transparente foi utilizado como testemunha, já o filtro vermelho foi utilizado para verificar se havia algum efeito sobre a taxa fotossintética das plantas. Apesar de não ter sido avaliada especificamente a taxa fotossintética, foi possível verificar através do acúmulo de massa seca que as diferenças entre os filtros não foram devido à alteração na fotossíntese, porque o filtro vermelho teoricamente teria um efeito maior sobre a fotossíntese, já que ele diminui drasticamente a radiação na faixa do azul (Figura 1). Por outro lado, esse filtro praticamente não afeta a razão entre o $\mathrm{V}$ e $\mathrm{Ve}$, podendose inferir que não houve efeito sobre a taxa fotossintética, já que os efeitos entre o filtro transparente e o filtro vermelho foram semelhantes para todas as variáveis analisadas. Diferentemente disso, o filtro verde apresentou efeitos sobre a emissão e acumulação de MS nos afilhos, ou seja indicando que esses efeitos foram em decorrência da alteração na razão entre a luz V e Ve (Figura 1).

A redução da qualidade da luz, através da aplicação de luz Ve a diferentes distâncias (direta, $60 \mathrm{~cm} \mathrm{e} 180 \mathrm{~cm}$ ) proporcionou resposta variável nos diferentes parâmetros analisados. As plantas que estavam localizadas imediatamente embaixo da luz Ve apresentaram menor acúmulo de MS no A1 e

Tabela 1 - Massa seca (MS) de afilhos em 20 plantas (g), MS por afilho (mg), percentagem de afilhos emitidos, massa seca do colmo principal (CP) e razão de massa seca entre o $\mathrm{CP}$ e os afilhos de trigo em função de tratamentos com filtro vermelho, verde e transparente na entrelinha, (primeiro experimento), da aplicação de radiação vermelha (V) a $180 \mathrm{~cm}$, a $60 \mathrm{~cm}$ e direta (segundo experimento) e da aplicação de radiação vermelha extrema (Ve) a $180 \mathrm{~cm}$, a $60 \mathrm{~cm}$ e direta (terceiro experimento) entre os estádios 1 e 3.1 da escala Haun. FA/UFRGS, Porto Alegre, RS, 1996

\begin{tabular}{|c|c|c|c|c|c|c|c|c|c|c|c|c|}
\hline & $\begin{array}{l}\text { MS do } \\
\text { A1 } \\
* *\end{array}$ & $\begin{array}{l}\text { MS do } \\
\text { A2 }\end{array}$ & $\begin{array}{l}\text { MS do } \\
\text { A3 }\end{array}$ & $\begin{array}{l}\text { MS/ } \\
\text { afilho do } \\
\text { A1 }\end{array}$ & $\begin{array}{l}\text { MS/ } \\
\text { afilho do } \\
\text { A2 }\end{array}$ & $\begin{array}{l}\text { MS/ } \\
\text { afilho do } \\
\text { A3 }\end{array}$ & $\%$ de $\mathrm{A} 1$ & $\%$ de $\mathrm{A} 2$ & $\%$ de $\mathrm{A} 3$ & $\begin{array}{l}\text { MS CP } \\
(\mathrm{g})\end{array}$ & $\begin{array}{l}\text { MS total } \\
(\mathrm{g})\end{array}$ & $\begin{array}{l}\text { Razão } \\
\text { CP/afilhos }\end{array}$ \\
\hline \multicolumn{13}{|c|}{ Primeiro experimento } \\
\hline $\begin{array}{l}\text { Filtro } \\
\text { Vermelho } * *\end{array}$ & $1,03 \mathrm{ab}^{*}$ & $0,47 \mathrm{a}$ & ----- & $62 \mathrm{a}$ & $31 \mathrm{a}$ & ----- & $83,0 \mathrm{a}$ & $76,0 \mathrm{a}$ & ----- & $3,14 \mathrm{ab}$ & $4,65 \mathrm{a}$ & $2,17 \mathrm{~b}$ \\
\hline Filtro verde & $0,81 \mathrm{~b}$ & $0,14 \mathrm{~b}$ & ---- & $58 \mathrm{a}$ & $16 \mathrm{~b}$ & ---- & $70,0 \mathrm{a}$ & $45,0 \mathrm{~b}$ & ---- & $2,92 \mathrm{~b}$ & $3,88 \mathrm{~b}$ & $3,12 \mathrm{a}$ \\
\hline $\begin{array}{l}\text { Filtro } \\
\text { transparente }\end{array}$ & $1,22 \mathrm{a}$ & $0,46 a$ & ---- & $70 \mathrm{a}$ & $32 \mathrm{a}$ & ---- & $82,0 \mathrm{a}$ & $72,0 \mathrm{a}$ & ---- & $3,38 \mathrm{a}$ & $5,07 \mathrm{a}$ & $2,08 \mathrm{~b}$ \\
\hline Média & 1,02 & 0,36 & & 63 & 26 & & 78,3 & 64,3 & & 3,15 & 4,53 & 2,46 \\
\hline $\mathrm{CV}(\%)$ & 22,8 & 26,4 & & 23,7 & 16,7 & & 15,7 & 19,6 & & 5,67 & 10,6 & 19,06 \\
\hline \multicolumn{13}{|c|}{ Segundo experimento } \\
\hline $\mathrm{V}$ a $180 \mathrm{~cm}$ & $0,52 b^{*}$ & $0,30 \mathrm{c}$ & ---- & $35 \mathrm{~b}$ & $20 \mathrm{~b}$ & ---- & $75,0 \mathrm{~ns}$ & $73,8 \mathrm{~b}$ & ---- & $2,06 \mathrm{~b}$ & $2,88 \mathrm{c}$ & $2,57 \mathrm{a}$ \\
\hline $\mathrm{V} \mathrm{a} 60 \mathrm{~cm}$ & $0,72 \mathrm{~b}$ & $0,50 \mathrm{~b}$ & ---- & $47 a$ & $33 a$ & ---- & 77,5 & $75,0 \mathrm{~b}$ & ---- & $2,21 \mathrm{~b}$ & $3,43 \mathrm{~b}$ & $1,84 \mathrm{~b}$ \\
\hline $\mathrm{V}$ direto & $0,99 \mathrm{a}$ & $0,76 a$ & ----- & $53 \mathrm{a}$ & $40 \mathrm{a}$ & ----- & 92,5 & $95,0 \mathrm{a}$ & ---- & $2,45 \mathrm{a}$ & $4,21 \mathrm{a}$ & $1,41 \mathrm{~b}$ \\
\hline Média & 0,74 & 0,52 & & 45 & 31 & & 81,7 & 81,3 & & 2,24 & 3,51 & 1,94 \\
\hline $\mathrm{CV}(\%)$ & $4,6^{* * *}$ & $2,99 * * *$ & & 12,8 & 15,6 & & 14,1 & 10,2 & & 5,9 & 8,9 & 17,2 \\
\hline \multicolumn{13}{|c|}{ Terceiro experimento } \\
\hline Ve a $180 \mathrm{~cm}$ & $0,35 a^{*}$ & $0,57 \mathrm{~ns}$ & $0,030 \mathrm{~b}$ & $45 \mathrm{~b}$ & $29 \mathrm{~ns}$ & $14 \mathrm{~b}$ & $36,8 \mathrm{a}$ & $95,0 \mathrm{~ns}$ & $7,5 \mathrm{c}$ & $2,61 \mathrm{a}$ & $3,55 \mathrm{~ns}$ & $2,82 \mathrm{~b}$ \\
\hline Ve a $60 \mathrm{~cm}$ & $0,41 \mathrm{a}$ & 0,41 & $0,329 a$ & $87 a$ & 25 & $70 \mathrm{a}$ & $24,7 \mathrm{ab}$ & 85,0 & $27,3 \mathrm{~b}$ & $2,19 \mathrm{~b}$ & 3,35 & $1,93 \mathrm{~b}$ \\
\hline Ve direto & $0,14 \mathrm{~b}$ & 0,42 & $0,062 \mathrm{~b}$ & $67 a b$ & 31 & $6 \mathrm{~b}$ & $10,2 \mathrm{~b}$ & 70,0 & $51,2 \mathrm{a}$ & $2,49 \mathrm{ab}$ & 3,12 & $4,22 \mathrm{a}$ \\
\hline Média & 0,30 & 0,47 & 0,140 & 66,3 & 28,3 & 30 & 23,9 & 83,3 & 28,7 & 2,43 & 3,34 & 2,99 \\
\hline $\mathrm{CV}(\%)$ & 38,1 & 22,1 & $5,98 * * *$ & $1,09 * * *$ & $0,18 * * *$ & $1,68^{* * *}$ & $29,2 * * *$ & 20,4 & $21,4 * * *$ & 9,63 & 11,4 & 26,8 \\
\hline
\end{tabular}

* Médias não seguidas por mesma letra na vertical, em cada experimento, diferem entre si, pelo teste de Duncan em nível de $5 \%$ de probabilidade de erro.

** A1 = afilho do nó da primeira folha; A2 = afilho do nó da segunda folha; A3 = afilho do nó da terceira folha.

*** Dados transformados por Raiz quadrada de X+1. 
A3, maior razão de MS entre o $\mathrm{CP}$ e os afilhos e menor emissão do A1 (Tabela 1).

A melhoria da qualidade da luz foi obtida através do uso de radiação Vermelha Direta. Esse tratamento resultou em efeito oposto ao descrito para os de baixa qualidade de luz. Foi constatado maior acúmulo de MS no $\mathrm{CP}$, em toda a planta e nos afilhos A1 e A2, menor razão de MS entre o $\mathrm{CP}$ e os afilhos e maior emissão do A2 (Tabela 1). O efeito da melhoria da qualidade da luz foi proporcional à distância que as plantas estavam da fonte de luz, ou seja, quanto mais próximo da luz vermelha melhor o resultado em termos emissão de afilhos e distribuição equilibrada de MS entre o CP e os afilhos.

A razão da modificação de alocação de massa seca, quando foi alterada a qualidade da luz, não está esclarecida. Quando há mudança na percepção do sinal pelo fitocromo e ocorre resposta da planta, possivelmente haja a participação de genes que modificam as relações entre reguladores de crescimento (ARNIM \& DENG, 1996; WEI \& DENG, 1996). Eles intermediariam as respostas de maior ou menor acúmulo de MS pelos afilhos quando se altera a qualidade da luz na comunidade. Entre os reguladores, possivelmente esteja envolvido o ácido indolacético, por alterar a dominância apical (ABEL \& THEOLOGIS, 1996), a giberelina, por alterar o alongamento celular (FOSTER et al., 1994; WELLER et al., 1994; JUEZ et al., 1995; REED et al., 1996) e a citocinina por estimular a iniciação da divisão celular em afilhos (WANG \& BELOW, 1996). Outra possibilidade é que o fitocromo esteja envolvido no controle de genes ligados à fotossíntese (DALE, 1988), como os que codificam a síntese de clorofila $a / b$, pequenas subunidades da Ribulose1,5-Bifosfato (Rubisco) e outros componentes do maquinário fotossintético.

O maior acúmulo de MS pelos afilhos, em ambiente de melhor qualidade da luz, poderia estar ligado ao maior crescimento foliar, que é devido, principalmente, ao aumento do número de células (DALE, 1988). Esses resultados estão de acordo com as observações de SKINNER \& NELSON (1995) de que a luz atua como um sinal precoce na divisão celular e que isso determina um maior crescimento foliar, que, por sua vez, está correlacionado com o aparecimento de novas folhas e afilhos (SKINNER \& NELSON, 1994a). As relações entre os afilhos e o CP se explicam porque os afilhos são dependentes do $\mathrm{CP}$, em fotoassimilados, até atingirem uma folha completamente expandida e, em nutrientes minerais, até iniciarem o desenvolvimento de suas raízes, o que começa a ocorrer após a emissão da terceira folha do CP (SKINNER \& NELSON, 1994b).
Os trabalhos realizados evidenciaram o efeito da qualidade da luz na determinação da emissão ou não de afilhos e na acumulação de massa seca por área destes, mas não permitiram estabelecer o grau de sensibilidade que as plantas apresentam à qualidade da luz de forma a afetar o potencial produtivo em comunidade. Isso porque as modificações na qualidade da luz foram aplicadas somente no período inicial do desenvolvimento das plantas e não é possível projetar os reflexos para todo o ciclo da planta.

Como a sobrevivência dos afilhos é afetada pela acumulação de MS (WOBETO, 1994), projeta-se um cenário em que a melhoria na qualidade da luz, nas fases iniciais do desenvolvimento das plantas, pode beneficiar o maior acúmulo de massa seca nos afilhos e possibilitar a sua viabilidade. Para tanto, poder-se-ia utilizar práticas que melhorem a qualidade da luz no início do desenvolvimento das plantas ou introduzir mecanismos de eliminação da percepção da proximidade das plantas, embora SÁNCHEZ et al. (1993) e BALLARÉ $\boldsymbol{e t}$ al. (1995) não acreditem que, necessariamente, resulte em aumento do potencial produtivo. Isso se confirma para plantas que afilham, já que a menor sensibilidade à luz permitiria a emissão de um grande número de afilhos e afilhos de maior massa, resultando em uma competição tão intensa, que a capacidade produtiva dessas plantas poderia ser comprometida, à semelhança do que ocorre em densidade de plantas extremamente elevadas.

Apesar disso, abrem-se perspectivas de desenvolvimento de novas técnicas para modificar a sensibilidade à qualidade da luz. Isso poderá ser feito através do uso de mutantes deficientes em fitocromo A (BALLARÉ $\boldsymbol{e t}$ al., 1994) ou em fitocromo B, que diminuem a percepção da razão V:Ve (BALLARÉ $\boldsymbol{e t}$ al., 1991; BALLARÉ et al.1992b) ou através da mudança da relação que há entre sensibilidade à luz e giberelina (REED et al., 1996), ácido abscísico (WEATHERWAX $\boldsymbol{e t} \boldsymbol{a l}$., 1996) ou a relação citocinina:auxina (HARRISON \& KAUFMAN, 1980).

\section{CONCLUSÕES}

A melhoria da qualidade da luz, obtida pela adição de luz vermelha, proporcionou maior emissão de afilhos e distribuição mais equilibrada de massa seca entre afilhos e o colmo principal.

A diminuição da qualidade da luz, obtida pela adição de luz vermelha extrema ou uso de filtro verde na entrelinha, determinou priorização no acúmulo de massa seca no colmo principal, o que resultou em menor emissão de afilhos e afilhos de menor massa seca.

Ciência Rural, v. 31, n. 3, 2001. 


\section{REFERÊNCIAS BIBLIOGRÁFICAS}

ABEL, S., THEOLOGIS, A. Early genes and auxin action Plant Physiology, Lancaster, v.111, n.1, p.09-17, 1996.

ARNIM, A., DENG, X.W. Light control of seedling development. Annual Review of Plant Physiology and Plant Molecular Biology, Stanford, v.47, p.215-43, 1996

BALLARÉ, C.L., CASAL, J.J., KENDRICK, R.E. Responses of wild-type and lh mutant seedlings of cucumber to natural and simulated shadelight. Photochemistry and Photobiology, Oxford, v.54, p.819-826, 1991.

BALLARÉ, C.L., SCOPEL, A.L., JORDAN, E., et al. Signaling among neighbouring plants and the development of size inequalities in plant populations. Ecology, New York, v.91, n.6, p.1094-1098, 1994.

BALLARÉ, C.L., SCOPEL, A.L., RADOSEVICH, S.R., et al Phytochrome-mediated phototropism in de-etioled seedling. Plant Physiology, Lancaster, v.100, n.1, p.170-177, 1992b.

BALLARÉ, C.L., SCOPEL A.L., SÁNCHEZ, R.A. Plant photomorphogenesis in canopies, crop growth, and yield. Hort Science, St. Joseph, v.30, n.6, p.1172-1181, 1995.

BALLARÉ, C.L., SÁNCHEZ, R.A., SCOPEL, A.L., et al. Early detection of neighbour plants by phytochrome perception of spectral changes in reflected sunlight. Plant Cell and Environment, Oxford, v.10, p.551-557, 1987.

BALLARÉ, C.L., SCOPEL, A.L., SÁNCHEZ, R.A., et al Photomorphogenic processes in the agricultural environment. Photochemistry and Photobiology, Oxford, v.56, p.777788, 1992a.

BARNES, C., BUGBEE, B. Morphological responses of wheat to changes in phytochrome photoequilibrium. Plant Physiology, Rockville, v.97, n.1, p.359-365, 1991.

CARDOSO, V.J.M. G erminação e fotoblastismo de sementes de Cucumis anguria: influência da qualidade da luz durante a maturação e secagem. Revista Brasileria de Fisiologia Vegetal, Londrina, v.7, n.1, p.75-80, 1995.

CASAL, J.J., DEREGIBUS, V.A., SÁNCHEZ, R.A. Variations in tiller dynamics and morphology in Lolium multiflorum Lam. vegetative and reproductive plants as affected by differences in red/far-red irradiation. Annals of Botany, London, v.56, p.533-559, 1985.

CASAL, J.J., SÁNCHEZ, R.A., DEREGIBUS, V.A. Effects of plant density on tillering: the involvement of the R/FR and proportion of radiation intercepted per plant. Environmental and Experimental Botany, Elmsford, v.26, p.365-371, 1986.

DALE, J.E. The control of leaf expansion. Annual Review of Plant Physiology and Plant Molecular Biology, Stanford, v.39, p.267-95, 1988

DAVIS, M.H., SIMMONS, S.R. Far-red light reflected from neighbouring vegetation promotes shoot elongation and accelerates flowering in spring barley plant. Plant Cell and Environment, Oxford, v.17, p.829-836, 1994.

DEREGIBUS, V.A., SÁNCHEZ, R.A., CASAL, J.J. Effects of light quality on tiller production in Lolium spp. Plant Physiology, Rockville, v.72, n.3, p.900-902, 1983.
FOSTER, K.R., MILLER F.R., CHILDS, K.L., et al. Genetic regulation of development in Sorghum bicolor. VIII. Shoot growth, tillering, flowering, gibberellin biosynthesis, and phytochrome levels are differentially affected by dosage of the ma3 allele. Plant Physiology, Lancaster, v.105, n.3, p.941-948, 1994.

GALLI, A.P. Competição intraespecífica e o crescimento de trigo e aveia em duas épocas de cultivo. Porto Alegre-RS, 1996. 78p. Dissertação (Mestrado em Fitotecnia) Programa de Pós graduação em Fitotecnia, Universidade Federal do Rio Grande do Sul, 1996.

HARRISON, M.A., KAUFMAN, P.B. Hormonal regulation of lateral bud (tiller) release in oats (Avena sativa L.). Plant Physiology, Lancaster, v.66, n.6, p.1123-1127, 1980.

HAUN, J.R. Visual quantification of wheat development. Agronomy Journal, Madison, v.65, n.1, p.116-119, 1973.

JUEZ, E.L., KOBAYASHI, M., SAKURAI, A., $\boldsymbol{e} t \boldsymbol{a l}$ Phytochrome, giberellins, and hypocotyl growth. A study using the cucumber (Cucumis sativus) long hypocotyl mutant. Plant Physiology, Rockville, v.107, n.1, p.131-140, 1995.

MARTIN, G.C. Apical dominance. Hort Science, St. Joseph, v.22, n.5, p.824-833, 1987.

MASLE, J. Competition among tillers in winter wheat: consequences for growth and development of the crops. In: NATO ADVANCED RESEARCH WORKSHOP ON WHEAT GROWTH AND MODELLING. 1985, New York. Proceeding... New York : Plenum, 1985. 407p. p.33-54. (NATO ASI Serie A, Live Science, v. 86).

MAAS, E.V., LESCH, S.M., FRANCOIIS, L.E., et al. Tiller development in salt-stressed wheat. Crop Science, Madison, v.34, n.6, p.1594-1603, 1994.

MEROTTO JUNIOR, A. Processo de afilhamento e crescimento de raízes de trigo afetados pela resistência do solo. Porto Alegre-RS, 1995. 114p. Dissertação (Mestrado em Fitotecnia) - Programa de Pós-graduação em Fitotecnia, Universidade Federal do Rio Grande do Sul, 1995.

REED, J.W., FOSTER, K.R., MORGAN, P.W., et al Phytochrome $\mathrm{b}$ affects responsiveness to gibberellins in Arabidopsis. Plant Physiology, Lancaster, v.112, n.1, p.337342, 1996.

SÁNCHEZ, R.A., CASAL, J.J., BALLARÉ, C.L., et al. Plant responses to canopy density mediated by photomorphogenic processes. In: INTERNATIONAL CROP SCIENCE CONGRESS, 1, 1993, Ames. Proceedings... Madison : Crop Science Society of America, 1993. p.779-786, 895p.

SCHMITT, J., WULFF, R.D. Light spectral quality phytochrome and plant competition. Tree Physiology, Victoria, v.8, p.47$51,1993$.

SKINNER, R.H., NELSON, C.J. Epidermal cell division and the coordination of leaf and tiller development. Annals of Botany, London, v.74, n.1, p.9-15, 1994a.

SKINNER, R.H., NELSON, C.J. ole of leaf appearance rate and the coleoptile tiller in regulation tiller production. Crop Science, Madison, v.34, n.1, p.71-75, 1994b. 
SKINNER, R.H., NELSON, C.J. Elongation of the grass leaf and its relationship to the phyllochron. Crop Science, Madison, v. 35, n.1, p.4-10, 1995 .

TAIZ, L., ZEIGER, E. Plant physiology. Redwood City : B. Cummings, 1991. 565p.

THIMIJAN, R.W., HEINS, R.D. Photometric, radiometric, and quantum light units of measure: a review of procedures for interconversion. Hort Science, St. Joseph, v.18, n.6, p.818$822,1983$.

WANG, X., BELOW, F.E. Cytokinins in enhanced growth and tillering of wheat induced by mixed nitrogen source. Crop Science, Madison, v.36, n.1, p.121-126, 1996

WEATHERWAX, S.C., ONG, M.S., DEGENHARDT, J., $\boldsymbol{e}$ t al The interaction of light and abscisic acid in the regulation of plant gene expression. Plant Physiology, Lancaster, v.111, n.2, p.363-370, 1996

WEI, N., DENG, X.W. The role of the COP/DET/FUS genes in light control of Arabidopsis seedling development. Plant Physiology, Lancaster, v.112, n.3, p.871-878, 1996.

WELLER, J.L., ROSS, J.J., REID, J.B. Giberellins and phytochrome regulation of stem elongation in pea. Planta Berlin, v.192, p.489/96, 1994.

WOBETO, C. Padrão de afilhamento, sobrevivência de afilhos e suas relações com o rendimento de grãos em trigo. Porto Alegre-RS, 1994. 102p. Dissertação (Mestrado em Fitotecnia) - Programa de Pós-graduação em Fitotecnia, Universidade Federal do Rio Grande do Sul, 1994.

Ciência Rural, v. 31, n. 3, 2001. 